28:619-24.

2. Suzuki S, Hayashi YK, Kuwana M, Tsuburaya R, Suzuki N, Nishino I. Myopathy associated with antibodies to signal recognition particle: disease progression and neurological outcome. Arch Neurol 2012; 69: 728-32.

3. Nakamura, T. Coexistence of Anti-SRP and Anti-SS-A/Ro Antibodies in Inflammatory Myopathy: Does the Association Occur by Chance? A Case Report. SN Compr. Clin. Med 2020; 2: 822-828.
4. Allenbach $\mathbf{Y}$, Mammen $A$, Benveniste $\mathbf{O}$, Stenzel W $224^{\text {th }}$ ENMC International Workshop: Clinico-sero-pathological classification of immune mediated necrotizing myopathies. Neuromuscular Disorders 2018; 28: 87-99.

5. Watanabe Y, Uruha A, Suzuki S, Nakahara J, Hamanaka K, Takayama K, et al. Clinical features and prognosis in anti-SRP and antiHMGCR necrotising myopathy. J Neurol Neurosurg Psychiatry 2016; 87:1038-44.

\title{
SO SÁNH GIỮA CHỤP XA HÌNH XƯƠNG VÀ CHỤP CẮT LỚP VI TÍNH TRONG PHÁT HIÊ̂N DI CĂN XƯO'NG Ở BÊNNH NHÂN UNG THƯ BIỂU MÔ TẾ BÀO GAN
}

\section{TÓM TẮT}

Mục tiêu: So sánh hiêu quả chẩn đoán di căn xương bằng chụp xạ hình xương (BS) với Technetium99m methylene diphosphonate (Tc-99m MDP) và chụp cắt lớp vi tính $(\mathrm{CT})$ ở bệnh nhân ung thư biểu mô tế bào gan (HCC) có nghi ngờ di căn xương. Phương pháp: Nghiên cứu tiến cứu trên 57 bệnh nhân HCC. Độ chính xác của $\mathrm{BS}$ và $\mathrm{CT}$ được xác định bằng cách so sánh với kết quả di căn tiến triển và chỉ định điều tri giảm nhẹ sau đó. Kết quả: Nghiên cứu này bao gồm 48 nam và 9 nữ, tuổi trung bình $60,5 \pm 12,9$. Lý do chụp xạ hình xương: tầm soát di căn $(54,4 \%)$, đau xương: $29,8 \%$, yếu chi: $14 \%$, sờ thây khối trên thành ngực: $1,8 \%$. Tî lệ phát hiện di căn xương bằng $\mathrm{BS}$ $(45,6 \%)$ cao hơn so với CT $(29,8 \%), p=0,001$. Có 23 vùng di căn trên $\mathrm{CT}$, có xu hướng phát hiện tốt hơn ở cột sống: $14 / 23$, xương chậu: $5 / 23$ và 45 vùng trên BS, có xu hướng phát hiện tổn thương tốt hơn ở cột sống: 19/45, xương sườn: 12/45. Theo kết quả theo dõi và điều trị giảm nhe bằng SBRT, phát hiện tổn thương xương di căn bẳng $\mathrm{CT}$ : đô nhay $72,2 \%$, độ đặc hiệu $89,7 \%$, giá trị dự đoán dương tính: 76,5\%, giá trị dự đoán âm tính $87,5 \%$, độ chính xác $84,2 \%$; phát hiện tổn thương xương di căn bằng bằng BS: độ nhạy $100 \%$, độ đặc hiệu 79,5\%, giá trị dự đoán dương tính $69,2 \%$, giá trị dự đoán âm tính $100 \%$, độ chính xác $86,0 \%$. Kết luân: Chụp xa hình xương có độ chính xác tốt hơn so với chụp cắt lớp vi tính trong việc phát hiện tổn thương xương do HCC di căn, nhưng để xác định di căn xương, hỏi bệnh cẩn thận, khám lâm sàng kĩ và thực hiện nhiều phương pháp chụp xương là rất quan trọng.

Tư khóa: Ung thư biểu mô tế bào gan, di căn xương, chụp xạ hình xương

\section{${ }^{1}$ Trường Đại học Y Dược Thái Nguyên}

²Bênh viện trung ương quân đội 108

Chịu trách nhiệm chính: Đồng Đức Hoàng

Email: Drhoang85@gmail.com

Ngày nhận bài: 21.12.2020

Ngày phản biện khoa học: 27.01.2021

Ngày duyệt bài: 2.2.2021
Đồng Đức Hoàng1, Lê Thị Ánh Tuyết ${ }^{2}$

\section{SUMMARY}

COMPARISON BETWEEN BONE SCINTIGRAPHY AND COMPUTED TOMOGRAPHY FOR THE

DETECTION OF BONE METASTASES IN HEPATOCELLULAR CARCINOMA

Aim: To compare the diagnostic accuracy of bone scintigraphy (BS) and computed tomography (CT) in detecting skeletal metastases for hepatocellular carcinoma (HCC) patients with suspicious bone metastasis. Methods: A prospective study was carried out in $57 \mathrm{HCC}$ patients. The accuracies of BS and $\mathrm{CT}$ were determined by comparing with final diagnosis with criteria obvious progression of the lesion revealed from the follow-up examinations and treatment. Results: This study included 48 male and 9 female, mean age $60.5 \pm 12.9$. Reasons for bone scintigraphy: Tumor extent surveillance: $54.4 \%$, bone pain: $29.8 \%$, limb weakness: $14 \%$, palpable chest wall mass: $1.8 \%$. There was a significant difference in bone metastatic detection between BS (45.6\%) and CT $(29.8 \%), p=0.001$. There were 23 metastatic regions on $\mathrm{CT}$, tended to identify more positive lesions in the spine: $14 / 23$, pelvis: $5 / 23$; 45 regions in $B S$, tended to show more positive lesions in the spine: 19/45, ribs: 12/45. According to the follow-up result and palliative treatment by SBRT, for detecting metastatic bone lesions by CT: Sensitivity $=72.2 \%$, Specificity $=89.7 \%$, Positive Predictive Value = $76.5 \%$, Negative Predictive Value $=87.5 \%$, Accuracy $=84.2 \%$; by BS: Sensitivity $=100 \%$, Specificity = $79.5 \%$, Positive Predictive Value $=69.2 \%$, Negative Predictive Value $=100 \%$, Accuracy $=86.0 \%$. Conclusion: BS has significantly better accuracy than $\mathrm{CT}$ in detecting metastatic HCC bone lesions, but to determine bone metastases, careful history taking, meticulous physical examination and perfoming many bone scan methods are very important.

Keyword: Hepatocellular carcinoma, Bone metastasis, Tc-99m MDP bone scintigraphy

\section{I. ĐẶT VẤN ĐỀ}

Ung thư biểu mô tế bào gan (HCC) là bệnh ác tính tại gan gặp nhiều nhất ở người trưởng 
thành[1]. Hiệu quả điều trị hiện nay đã được cải thiện đáng kể với sự trợ giúp của các phương tiên chẩn đoán hình ảnh hiên đại, giúp cho các bác sĩ chuyên ngành chẩn đoán bệnh sớm hơn, giai đoạn bệnh được phân loại chính xác hơn nên phác đồ điều trị sát với bệnh nhân hơn[2].

Chẩn đoán chính xác giai đoạn bệnh rất quan trong, quyết định chiến lược điều trị, nếu khối u vẫn khu trú tại gan, các phương pháp triệt căn có thể sử dụng như cắt gan, đốt nhiệt sóng cao tần, tiêm ethanol qua da, thậm chí là ghép gan. Trái lại, nếu xác định có di cằn ngoài gan thì các phương pháp được lựa chọn là điều trị hóa chất và giảm nhẹ[3]. Phổi, hạch ổ bụng, xương là những cơ quan hay gặp nhất khi tế bào ác tính di căn ra ngoài gan[2]. Chụp cắt lớp vi tính là phương pháp phổ biến nhất để phát hiện những dấu hiệu bất thường ở các cơ quan này.

Riêng với các tổn thương nghi di căn xương, chụp xạ hình xương cũng là một phương pháp hiệu quả để chẩn đoán di căn[4],[5]. Một số trung tâm coi xạ hình xương là phương pháp chẩn đoán hình ảnh tốt nhất để phát hiện sớm di căn xương ở bệnh nhân HCC[2],[ 6]. Tuy nhiên liệu khi xạ hình xương không thấy tổn thương chúng ta có thể loại trừ tình trạng di căn cho bệnh nhân khi mà có những báo cáo cho thây tỉ lệ âm tính giả là khá cao[7]. Vì vậy nên cần thêm những số liệu để có cái nhìn khách quan về độ chính xác trong chẩn đoán di căn xương[8]. Chúng tôi tiến hành nghiên cứu này nhằm mục tiêu:

- So sánh hiệu quả chẩn đoán di căn xương bằng chụp xạ hình xương và chụp cắt lớp vi tính ở bệnh nhân ung thư biểu mô tế bào gan có nghi ngờ di căn xương.

\section{II. ĐỐI TƯỢNG VÀ PHƯƠNG PHÁP NGHIÊN CỨU \\ 2.1.Đối tượng nghiên cứu}

- Tiêu chuẩn chọn đối tượng nghiên cứu:

+ Bệnh nhân được chẩn đoán HCC dựa trên hướng dẫn chẩn đoán HCC của Hiệp hội nghiên cứu bênh gan Hoa Kỳ AASLD năm 2005 (khối u gan có hình ảnh tăng sinh mạch điển hình trên chụp CT có tiêm thuốc cản quang hoă̆c chụp MRI có tiêm thuốc đối quang từ hoặc bằng kết quả mô bệnh học).

+ Bệnh nhân được chụp CT và chụp xạ hình xương để phát hiện di căn xương.

- Tiêu chuẩn loại trừ: dị ứng với thuốc cản quang, không đồng ý tham gia nghiên cứu.

\subsection{Thời gian, địa điểm nghiên cứu}

- Thời gian nghiên cứu: Từ tháng 10 năm 2017 đến tháng 4 năm 2020.

- Địa điểm nghiên cứu: Bệnh viện Trung ương quân đội 108, Hà Nội.

\subsection{Phương pháp nghiên cứu}

- Thiết kế tiến cứu, mô tả đánh giá nghiệm pháp chẩn đoán.

\subsection{Cỡ mẫu nghiên cứu}

*Cỡ mẫu: chọn cõ̃ mẫu thuân tiện. Do số bệnh nhân HCC có di căn xương là khồng nhiều, tî lệ chỉ là $1,9 \%$ nên chúng tôi chọn các bệnh nhân đủ tiêu chuẩn vào nghiên cứu[1].

\subsection{Các bước tiến hành nghiên cứu}

- Hỏi thông tin nhân khẩu học, yếu tố nguy cơ HCC và khám triệu chứng của HCC.

- Các bệnh nhân được làm các xét nghiệm công thức máu và đông máu bằng máy Cell Dyn 3700 (Abbot) tại khoa Huyết học. Xét nghiệm sinh hóa bằng máy Olympus Au 640 tại khoa Sinh hóa. Xét nghiệm AFP, HbsAg, anti HCV bằng phương pháp ELISA thực hiện tại khoa Miễn dịch. Chụp $\mathrm{CT}$ ổ bụng bằng máy Brivo CT385. Chụp xạ hình xương toàn thân (Whole Body Scan) 3 giờ sau tiêm tĩnh mạch $15 \mathrm{mCi}$ Tc99m-MDP bằng hệ thống GE Medical System.

- Các bệnh nhân phát hiện có di căn xương trên CT hoặc xạ hình xương sau đó được theo dõi để khẳng định có di căn xương. Cách nhân đinh kết quả theo dõi: Biểu hiện lâm sàng nặng hơn, đau xương tăng, tổn thương khu trú tại xương tiến triển, bệnh nhân được chụp mô phỏng và điêu trị giảm nhẹ bằng xạ trị xương (SBRT).

- Đánh giá giá trị của CT và chụp xạ hình xương trong chẩn đoán di căn xương bằng đối chiếu với chẩn đoán sau theo dõi là chẩn đoán cuối cùng.

- Thu thập số liệu theo mẫu bệnh án chung thống nhất.

\subsection{Chỉ tiêu nghiên cứu}

*Chỉ tiêu lâm sàng:

- Giới: nam, nữ. Nguyên nhân HCC: viêm gan B, C, khác.

- Lí do chỉ định chup xa hình xương: đau xương, yếu chi, sờ thấy khối trên da.

*Phân loại giai đoạn xơ gan theo Child Pugh.

*Chỉ tiêu trên hình ảnh CT:

- Vị trí u gan: thùy gan phải, thùy gan trái, 2 thùy.

- Số lượng u: đếm số u trên hình ảnh chụp CT.

- Kích thước u: Tổng đường kính lớn nhất của tất cả các khối u trên CT.

- Di căn: phổi, hạch, xương.

*Các chỉ tiêu về chụp xa hình xương:

- Các vị trí xương di căn trên xạ hình: gò má, cột sống, bả vai, ức, sườn, chậu, chi.

2.7.Xử lý số liệu. Số liệu được xử lý bằng phần mềm thống kể y học SPSS 22.0. Phân tích các số liệu bằng thuật toán thống kê mô tả tần số các biến Frequencies. Phân tích tỉ lệ giữa 2 
biến bằng Crosstab, kiểm định Chi square, kết quả có ý nghĩa khi $\mathrm{p}<0,05$. Độ nhạy $(\mathrm{Sn})$, độ đặc hiệu (Sp), giá trị dự đoán dương tính (PPV), giá trị dự đoán âm tính (NPV) và chẩn đoán chính xác phương pháp (Ac).

\section{KẾT QUẢ NGHIÊN CỨU}

Bảng 1: Đặc điểm chung của đôî tượng nghiên cứlu

\begin{tabular}{|c|c|c|c|}
\hline \multicolumn{2}{|c|}{ Đăcc điếm } & N (57) & $\%$ \\
\hline \multicolumn{2}{|c|}{ Tuối trung bình } & \multicolumn{2}{|c|}{$60.5 \pm 12.9$} \\
\hline \multirow{2}{*}{ Giới } & Nam & 48 & 84.2 \\
\hline & Nữ & 9 & 15.8 \\
\hline \multirow{4}{*}{$\begin{array}{c}\text { Lí do xạ } \\
\text { hình } \\
\text { xương }\end{array}$} & Tầm soát di căn & 31 & 54.4 \\
\hline & Đau xương & 17 & 29.8 \\
\hline & Yếu chi & 8 & 14.0 \\
\hline & Sờ thấy khối & 1 & 1.8 \\
\hline \multirow{4}{*}{$\begin{array}{c}\text { Nguyên } \\
\text { nhân }\end{array}$} & Viêm gan $B$ & 35 & 61.4 \\
\hline & Viêm gan C & 3 & 5.3 \\
\hline & Viêm gan $B, C$ & 3 & 5.3 \\
\hline & Khác & 16 & 28.1 \\
\hline \multirow{2}{*}{$\begin{array}{l}\text { Child } \\
\text { Pugh }\end{array}$} & A & 56 & 98.2 \\
\hline & B & 1 & 1.8 \\
\hline \multirow{2}{*}{$\begin{array}{c}\text { AFP } \\
(\mathrm{ng} / \mathrm{ml})\end{array}$} & $<20$ & 23 & 40.4 \\
\hline & $20-200$ & 10 & 17.5 \\
\hline
\end{tabular}

$$
>200
$$

Nhận xét: Tuối trung bình của bệnh nhân là $60.5 \pm$ 12.9. Tỉ lệ nam là $84.2 \%$. Lí do bệnh nhân được chụp xạ hình xương chủ yếu là đau xương $(29.8 \%)$, yếu chi chiếm tỉ lê thấp hơn $(14 \%)$, chỉ có 1 bệnh nhân sờ thấy khối u trên da $(1.8 \%)$.

Bảng 2: Đăc điểm trên phim chụp CT

\begin{tabular}{|c|c|c|c|}
\hline \multicolumn{2}{|c|}{ Đắc điếm } & $\mathbf{N}$ (57) & $\mathbf{\%}$ \\
\hline \multirow{3}{*}{ Vị trí u u } & Gan trái & 3 & 5.3 \\
\cline { 2 - 4 } & Gan phải & 48 & 84.2 \\
\cline { 2 - 4 } & 2 thùy & 6 & 10.5 \\
\hline Số & 1 ố & 34 & 59.6 \\
\cline { 2 - 4 } lượng u & Đa ố & 23 & 40.4 \\
\hline \multirow{2}{*}{$\begin{array}{c}\text { Kích } \\
\text { thước u u } \\
\text { (cm) }\end{array}$} & $<5$ & 21 & 36.8 \\
\cline { 2 - 4 } & $5-10$ & 29 & 50.9 \\
\cline { 2 - 4 } Di căn & $>10$ & 7 & 12.3 \\
\cline { 2 - 4 } & Phối & 3 & 5.3 \\
\cline { 2 - 4 } & Hạch & 5 & 8.8 \\
\hline
\end{tabular}

Nhận xét: Tỉ lệ u gan phải chiếm tî lệ cao nhất $84.2 \%$. Số lượng u đơn độc chiếm tỉ lệ cao hơn với $59.6 \%$. Nhóm kích thước u từ $5-10 \mathrm{~cm}$ chiếm tỉ lệ cao nhất với $50.9 \%$. Tỉ lệ bệnh nhân có di căn phổi là $5.3 \%$, di căn hạch là $8.8 \%$.

Bảng 3: Sự khác nhau giữa phát hiện di căn xương bằng CT và xạ hình xương

\begin{tabular}{|c|c|c|c|c|c|c|c|c|}
\hline & \multicolumn{4}{|c|}{ Xạ hình xương } & \multirow{3}{*}{\multicolumn{2}{|c|}{ Tổng }} & \multirow{3}{*}{$\mathbf{p}$} \\
\hline & & \multicolumn{2}{|c|}{ Di căn } & \multicolumn{2}{|c|}{ Không di căn } & & & \\
\hline & & $\mathbf{n}$ & $\%$ & $\mathbf{n}$ & $\%$ & & & \\
\hline \multirow{2}{*}{$\begin{array}{c}\text { CT } \\
\text { xương }\end{array}$} & Di căn & 15 & 26.3 & 2 & 3.5 & 17 & 29.8 & \multirow{3}{*}{0.001} \\
\hline & Không di căn & 11 & 19.3 & 29 & 50.9 & 40 & 70.2 & \\
\hline & Tống & 26 & 45.6 & 31 & 54.4 & 57 & 100 & \\
\hline
\end{tabular}

Nhận xét: Trong tổng số 57 bệnh nhân, chụp CT phát hiện được 17 bệnh nhân có di căn xương, tỉ lệ $29.8 \%$. Chụp xạ hình xương phát hiện được 26 bệnh nhân có di căn xương, chiếm tỉ lệ 45.6\%, sự khác biệt có ý nghĩa $p<0,05$.

Bảng 4: Vị trí tổn thương xương trên $C T$ và xạ hình xương

\begin{tabular}{|c|c|c|c|c|}
\hline \multirow{2}{*}{ Vị trí } & \multicolumn{2}{|c|}{ CT xương } & \multicolumn{2}{c|}{ Xạ hình xương } \\
\cline { 2 - 5 } & $\mathbf{n}$ & $\mathbf{\%}$ & $\mathbf{n}$ & $\mathbf{\%}$ \\
\hline Xương gò má & 0 & 0 & 1 & 2.2 \\
\hline Xương cột sống & 14 & 60.9 & 19 & 42.2 \\
\hline Xương bả vai & 0 & 0 & 3 & 6.7 \\
\hline Xương ức & 1 & 4.3 & 1 & 2.2 \\
\hline Xương sườn & 2 & 8.7 & 12 & 26.7 \\
\hline Xương chậu & 5 & 21.7 & 6 & 13.3 \\
\hline Xương chi & 1 & 4.3 & 3 & 6.7 \\
\hline Tống số & $\mathbf{2 3}$ & $\mathbf{1 0 0}$ & $\mathbf{4 5}$ & $\mathbf{1 0 0}$ \\
\hline
\end{tabular}

Nhận xét: Trên hình ảnh CT phát hiện được 23 vị trí di căn xương, trong đó di căn xương cột sống chiếm tỉ lệ cao nhất $60.9 \%$, cao thứ 2 là di căn xương chậu $21.7 \%$. Kết quá xạ hình xương cho thấy có 45 vị trí di căn xương, cột sống vẫn là nơi di căn nhiều nhất $42.2 \%$, xương sườn cao

thứ 2 với $26.7 \%$.

Bảng 5: Giá trị của CT trong chẩn đoán di căn xương

\begin{tabular}{|c|c|c|c|c|}
\hline \multicolumn{2}{|c|}{} & \multicolumn{2}{|c|}{ Chấn đoán cuối cùng } & \multirow{2}{*}{ Tổng } \\
\cline { 3 - 5 } \multicolumn{2}{c|}{} & Di căn & Không di căn & \\
\hline \multirow{2}{*}{$\begin{array}{c}\text { CT } \\
\text { xương }\end{array}$} & Di căn & 13 & 4 & 17 \\
\cline { 2 - 5 } & $\begin{array}{c}\text { Không } \\
\text { di căn }\end{array}$ & 5 & 35 & 40 \\
\cline { 2 - 5 } & Tống & $\mathbf{1 8}$ & $\mathbf{3 9}$ & $\mathbf{5 7}$ \\
\hline
\end{tabular}

Nhận xét: So sánh kết quả phát hiện di căn xương bằng chụp $\mathrm{CT}$ thấy rằng: độ nhạy (Sensitivity $-\mathrm{Sn})=13 / 18=72.2 \%$. Độ đặc hiệu (Specificity - Sp) $=35 / 39=89.7 \%$. Giá trị dự đoán dương tính (Positive Predictive Value - PPV) $=13 / 17=76.5 \%$. Giá trị dự đoán âm tính (Negative Predictive Value - NPV) = $35 / 40=87.5 \%$. Chẩn đoán chính xác phương pháp $($ Accuracy $-A c)=(13+35) / 57=84.2 \%$. 
Bảng 6: Giá trị của xạ hình xương trong chẩn đoán di căn xương

\begin{tabular}{|c|c|c|c|c|}
\hline \multicolumn{2}{|c|}{} & \multicolumn{2}{|c|}{$\begin{array}{c}\text { Chấn đoán } \\
\text { cuối cùng }\end{array}$} & \multirow{2}{*}{ Tổng } \\
\cline { 3 - 5 } \multicolumn{2}{|c|}{} & $\begin{array}{c}\text { Di } \\
\text { Căn }\end{array}$ & $\begin{array}{c}\text { Không } \\
\text { di căn }\end{array}$ & \\
\hline \multirow{2}{*}{$\begin{array}{c}\text { Xàn } \\
\text { hình } \\
\text { xươnng }\end{array}$} & Di căn & 18 & 8 & 26 \\
\cline { 2 - 5 } & Không di căn & 0 & 31 & 31 \\
\cline { 2 - 5 } & Tống & $\mathbf{1 8}$ & $\mathbf{3 9}$ & $\mathbf{5 7}$ \\
\hline
\end{tabular}

Nhận xét: So sánh kết quả phát hiện di căn xương bằng chụp $\mathrm{CT}$ thấy rằng: độ nhạ $($ Sensitivity $-\mathrm{Sn})=18 / 18=100 \%$. Độ đặc hiệu (Specificity - Sp) $=31 / 39=79.5 \%$. Giá trị dự đoán dương tính (Positive Predictive Value - PPV) $=18 / 26=69.2 \%$. Giá trị dự đoán âm tính (Negative Predictive Value - NPV) = $31 / 31=100 \%$. Chẩn đoán chính xác phương pháp $($ Accuracy $-A c)=(18+31) / 57=86.0 \%$.

\section{BÀN LUÂ̂N}

Trên bệnh nhân HCC tình trạng di căn tế bào ác tính đến các cơ quan trong cơ thể thường hay xảy ra, trong đó những vị trí lân cận như phổi, ống tiêu hóa, xương là hay gặp nhất. Nhóm bệnh nhân chúng tôi chọn để đánh giá tình trạng di căn xương này có tuổi trung bình là $60.5 \pm$ 12.9, gần tương đương với nhóm bệnh nhân của Yen RF và cs là $61.0 \pm 12.0$, tỉ lệ nam nữ của tác giả là 29/5 cũng tương đồng với của chúng tôi 48/9[3]. Vì đây là nghiên cứu để so sánh độ chính xác của hai phương pháp chụp $\mathrm{CT}$ và chụp xạ hình xương để phát hiện di căn, ban đẩu chưa xác định được di căn, nên chúng tôi không phân loại giai đoạn HCC, hiện nay BCLC là phân loại thường được sử dụng nhất nhưng có và không di căn xương làm cho bệnh nhân được chẩn đoán giai đoạn hoàn toàn khác nhau. Cùng với xét nghiệm máu và xét nghiệm AFP để đánh giá chức năng gan và đáp ứng sinh học khối u, chúng tôi chỉ định cho bệnh nhân chụp CT ổ bụng để đánh giá tình trạng khối u và các tổn thương thứ phát khác. Về đặc điểm khối u gan nguyên phát thì cũng không có gì đặc biệt.

Số bệnh nhân có biểu hiện lâm sàng của di căn xương không phải là nhiều, đau xương là lí do thường gặp nhất bệnh nhân kể cho bác sĩ, tỉ lệ bệnh nhân giảm vận động, cảm giác yếu chi còn thấp hơn và chỉ có 1 bệnh nhân vào viện vì lí do là đau vùng mạn sườn phải, khám lâm sàng chúng tôi sờ thấy một khối u ở dưới da. Phần lớn các bệnh nhân khác được chỉ định chụp $C T$ và chụp xạ hình xương với mục đích tầm soát di căn dù không có biểu hiện gì trên lâm sàng. Trong thực hành lâm sàng thực tế hiện nay, chụp xạ hình xương toàn thân với Tc-99m MDP vẫn được sử dụng rộng rãi vì là phương pháp có giá thành hợp lí để tầm soát cho các bệnh nhân có nghi ngờ di căn xương nguồn gốc từ các loại ung thư trong hàng thập kỉ nay[3],[ 4]. Phương pháp chụp này biểu diễn một hình quét hai chiều toàn thân để chiếu lên hình ảnh xương toàn thân trong một lát cắt[3]. Đã có những báo cáo rằng chụp xạ hình xương toàn thân có thể cho kết quả âm tính giả với các tổn thương di căn có tiêu hủy xương bởi vì thiếu phản ứng với tế bào tạo xương ngoại vi[7]. Chính vì lí do này nên khi so sánh kết quả chụp CT các vị trí nghi ngờ di căn với chụp xạ hình xương chúng tôi thấy có hai bệnh nhân trên hình ảnh $C T$ có hình ảnh ổ khuyết xương không đều ở vị trí thân đốt L3,L4, kèm theo nốt đặc xương thân đốt $L 1, L 2$ nhưng kết quả chụp xạ hình xương không phát hiện bất thường. Tuy vậy $\mathrm{CT}$ cũng có những hạn chế khi mà có tới $19.3 \%$ số bệnh nhân không phát hiện được tổn thương mặc dù chúng tôi đã chỉ định cho bệnh nhân chụp 320 lát cắt, trên hình ảnh chụp xạ hình xương lại phát hiện được những tổn thương di căn này.

Khi thống kê các vị trí di căn xương chúng tôi thây trên hình ảnh xạ hình xương phát hiện được nhiều hơn ở các xương nhỏ như xương sườn, xương chi, xương vai. Điều này có thể hiểu được vì khi tổn thương với kích thước rất nhỏ mà bệnh nhân lại không có biểu hiện lâm sàng cộng thêm các lát cắt $\mathrm{CT}$ không cắt qua tổn thương là những yếu tố làm cho các bác sĩ chẩn đoán hình ảnh không phát hiện ra tổn thương[3]. So sánh với chẩn đoán cuối cùng là kết quả theo dõi lâu dài và các bệnh nhân có di căn xương được chúng tôi chụp mô phỏng tổn thương và điều trị giảm nhe bằng tia xạ thì thây độ nhạy của $\mathrm{CT}$ là $72.2 \%$ thấp hơn độ nhạy của chụp xạ hình xương $100 \%$ trong phát hiện di căn xương. Tuy nhiên độ đặc hiệu của CT là $89.7 \%$ lại cao hơn so với độ đặc hiệu của chụp xạ hình xương là $79.5 \%$. Có tác giả báo cáo rằng $\mathrm{MRI}$ là phương pháp có độ phân giải tốt hơn trong phát hiện tổn thương di căn xương so với cả chụp xạ hình và CT, tác giả đề xuất chỉ nên dùng hai phương pháp này để sàng lọc ban đầu[3],[ 4]. Nghiên cứu khác chỉ ra rằng $57.5 \% \%$ tổn thương phát hiện ra trên xạ hình xương, SPECT/CT nên được sử dụng để xác định các tổn thương có calci hóa[6].

\section{KẾT LUẬN}

Chụp xạ hình xương 45.6\% phát hiện được di căn nhiêu hơn chụp CT $29.8 \%, p<0,05$. 
Vị trí xương di căn phát hiện bằng xa hình là 45, trên CT là 23.

Phát hiện di căn xương bằng chụp xạ hình có độ nhạy $100 \%$, độ đặc hiệu 79.5\%; CT độ nhạy $72.2 \%$, đô đặc hiệu $89.7 \%$.

Độ chính xác chẩn đoán của xạ hình xương $86.0 \%$ cao hơn của chụp CT 84.2\%.

\section{TÀI LIÊU THAM KHẢO}

1. Đào Đức Tiến. (2018). Đánh giá kết quả điều trị ung thư biểu mô tế bào gan bằng phương pháp tắc mach xạ trị với hạt vi cầu gắn YTTRIUM-90, Luận án tiến sĩ y học, Viện nghiên cứu khoa học Y dược lâm sàng 108.

2. Sakdapetsiri W. (2017). Agreement of bone metastasis detection between bone scintigraphy and whole body-MRI in hepatocellular carcinoma. Chula Med J, 61: 322-331.

3. Yen RF, Chen CY, Cheng MF, et al. (2010). The diagnostic and prognostic effectiveness of $\mathrm{F}$ 18 sodium fluoride PET-CT in detecting bone metastases for hepatocellular carcinoma patients. Nucl Med Commun., 31(7):637-45.
4. Langsteger $W$, Rezaee $A$, Pirich $C$, et al. (2016). 18F-NaF-PET/CT and 99mTc-MDP Bone Scintigraphy in the Detection of Bone Metastases in Prostate Cancer. Semin Nucl Med, 46(6):491-501.

5. Verma S, Kumar N, Kheruka S, et al. (2016) Extraosseous 99mTc-methylene diphosphonate uptake on bone scan: Unusual scenario. Indian J Nucl Med, 31(4): 280-282.

6. Zhang L, He Q, Zhou T, et al. (2019). Accurate characterization of 99mTc-MDP uptake in extraosseous neoplasm mimicking bone metastasis on whole-body bone scan: contribution of SPECT/CT. BMC Medical Imaging, 19: 44.

7. Chen CY, Wu K, Lin WH, et al. (2012). High false negative rate of Tc-99m MDP whole-body bone scintigraphy in detecting skeletal metastases for patients with hepatoma. Journal of the Formosan Medical Association, 111(3): 140-146.

8. Bolaños DC, Wong LR, González DN, et al. (2017). Sensitivity, Specificity, Predictive Values, and Accuracy of Three Diagnostic Tests to Predict Inferior Alveolar Nerve Blockade Failure in Symptomatic Irreversible Pulpitis. Pain Research and Management, 2017, https:// doi.org/10.1155/2017/3108940.

\section{KIẾN THỨC, THÁI Độ TRONG PHÒNG CHỐNG VÀ CHĂM SÓC NGƯỜI NHIỄM HIV/AIDS CỦA SINH VIÊN ĐIỀU DƯỠNG TRƯỜ'NG ĐẠI HỌC Y HÀ NỘI VÀ THÀNH TÂY NĂM 2017}

Phạm Thị Thùy Dung*, Nguyễn Thị Hồng Anh*, Nguyễn Hồng Trang*

\section{TÓM TẮT}

Đặt vấn đề: Đánh giá kiến thức, thái độ về việc chăm sóc cho người nhiễm HIV/AIDS của sinh viển ngành Điều dưỡng - những người sẽ thường xuyên tiếp xúc, chăm sóc trực tiếp với các bênh nhân - là rất quan trọng. Tuy nhiển, tại Việt Nam có rất ít nghiên cứu thức hiên trên đối tượng này. Muc tiêu: Mô tả kiến thức, thái độ về phòng chống và chăm sóc người bênh HIV/AIDS của sinh viên năm thứ 3 và thứ 4 tai trường đại học $Y$ Hà Nội và đại học Thành Tây năm 2017; Xác định một số yếu tố liền quan giữa kiến thức với thái độ về phòng chống và chăm sóc người bệnh HIV/AIDS của đối tượng nghiên cứu. Phương pháp: Nghiên cứu mô tả cắt ngang có phân tích. Kết quả: Kiến thức, phòng chống và chăm sóc người bệnh HIV/AIDS của sinh viên điều dưỡng năm thứ 3 và thứ 4 tại hai trường chưa cao $(63 \%)$, trong đó tỷ lệ đạt ở sinh viên $Đ H$ Y Hà Nội là $80,1 \%$, và sinh viên trường ĐH Thành Tây là 41,2\%. Điểm trung bình chung về kiến thức HIV/AIDS đat của sinh viên của 2 trường là $20 \pm 3,2$, trong đó trường ĐH Y Hà Nội $(21,6 \pm 2,5)$ cao hơn điểm trung bình của sinh viên ĐH Thành Tây

* Dai hoc Phenikaa, Hà Nôi

Chịu trách nhiệm chính: Phạm Thị Thùy Dung Email: phamdung0610@gmail.com

Ngày nhân bài: 21.12.2020

Ngày phản biên khoa hoc: 27.01.2021

Ngày duyệt bài: 4.2.2021
$(18,4 \pm 3,8)$. Về thái độ: có tới $15,5 \%$ sinh viên có xa lánh, đồ lôi cho người có HIV; $9,1 \%$ sinh viên đồng ý/rất đồng ý rằng "người nghiện chích ma túy đáng bị mắc HIV"; và sinh viên có thái độ "đồng cảm" với "trẻ em/người nhiểm HIV do truyền máu hơn là người nhiễm HIV do tiêm chích ma túy" chiếm 34,3\%. Kết luân: Các trường đào tạo điều dưỡng cần trang bị thểm cho các em sinh viển kiến thức về dự phòng và chăm sóc người nhiễm HIV/AIDS, kiểm soát nhiễm khuẩn trong HIV/AIDS, từ đó giảm thái độ kỳ thị với người nhiễm HIV/AIDS.

\section{SUMMARY \\ KNOWLEDGE AND ATTITUDES IN THE \\ PREVENTION AND CARE FOR PATIENTS WITH HIV/AIDS AMONG NURSING STUDENTS OF HA NOI MEDICAL UNIVERSITY AND THANH TAY UNIVERSITY IN 2017 \\ Background: Nursing students are expected to} have certain knowledge and attitudes about caring for people with HIV/AIDS because they will play an important role in care for those patients in later career. However, in Vietnam, limit is known about their knowledge and attitudes about this issue. Objectives: (1) Describe knowledge and attitudes about and care for patient with HIV/AIDS among students of $3^{\text {rd }}$ and $4^{\text {th }}$ year at Hanoi Medical University and Thanh Tay University in 2017; (1) Identify some factors related to subjects knowledge of 